cat came to an untimely end eighteen months ago, but the only surviving kitten of the five named above is as fond of the dog as her mother was. She brings mice, young rats, and rabbits, and lays them down before "Cato," and looks beseechingly till he takes them. She constantly plays with him and gets on her hind legs to look fondly into his face, while he puts his paws round her as he used to do to her mother.

She must have inheriled this affection from her mother, as she was too young to have imitated her mother's actions at the time of her death.

Clent, July I3

\section{Scarcity of Birds}

I SHOULD much like to know whether blackbirds and thrushes are scarce in other localities this year; because they have most unaccountably vanished from this neighbourhood, with the excep. tion of a very few stragglers. Our cherries and strawberries are untouched. I have not observed a single blackbird or thrush in our garden or pleasure-grounds since the fruit ripened, though every olher year we captured several in the cherry-nets, and shot many others.

Fassaroe Dray, co. Wicklow, July I2

\begin{abstract}
R. M. BARRINGTON
\end{abstract}
\section{OUR ASTRONOMICAL COLUMN}

VARIABLE STARS.- Of the three stars to which Col. Tennant draws attention as being probably variable ("Monthly Notices R.A.S." June r875), B.A.C. 740 appears more especially deserving of regular observation. The B.A.C. has adopted the magnitude assigned by Groombridge, 6; other estimates are :-Hevelius, 6 ; Fedorenko (Lalande, 1789 November), 8 ; Piazzi, 8, by

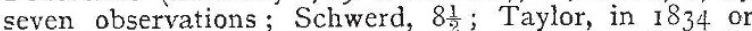
1835, in vol. iii. of "Madras Observations," 7 (he calls the star 2I Cephei); Carrington, 8.1; the Radcliffe Catalogues, 7.5 ; and Durchmusterung, 8.4 . With regard to the observation of Hevelius, which has been assumed to refer to this star, it may be remarked that the position given in his Catalogue for 1660 , where it is No. 46 in Cepheus, does not well agree with the place of the Redhill Catalogue for B.A.C. 740, the difference of position amounting to $16^{\prime}$; nevertheless it is not easy to identify the star observed by Hevelius with any other in the modern catalogues. In the cases of the stars B.A.C. 4166 and 4193 , also noticed by Col. Tennant, the estimates of magnitude from the epoch of Schwerd's observations to the present time appear pretty accordant. In comparing the magnitudes assigned in different catalogues to the naked-eye stars it is necessary to bear in mind that in Argelander's Uranometria, and in Heis and Behrmann, 6.5, 5.4, \&c., apply to stars which are judged to be somewhat brighter than an average sixth or fifth magnitude, and are not to be understood decimally, as is the case in the "Durchmusterung."]

TrE DOUBLE-STAR $\Sigma$ 1785.--The proper motion of this star is investigated in Argelander's researches, Bonn Observations, vol. 7. He remarks : "Die Begleiter geht mit," and of this there can be no doubt, since in the interval between Struve's first measures and the last published by the Baron Dembowski, the amount of proper motion, according to Argelander's values, would be $-20^{\prime \prime} \cdot 9$ in R.A. and $-2^{\prime \prime} \cdot 4$ in Decl. Dut the relative fixity of the components, which might have been surmised from Argelander's comparison of his differences of R.A. and Decl. for $1867^{\circ} 34$, with those decluced from Struve's angle and clistance in 1830 , is clearly refuted by the recent measures. Thus we have-

Struve $\ldots . \ldots \quad 1830^{\circ} 12$ Position $164^{\circ} \cdot 43$ Distance $3^{\prime \prime} 487$

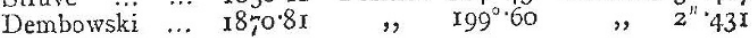

Perhaps it is not yet practicable to decide whether this relative change is due to slight difference of proper motion o: to the binary character of the star, but it is evidently one that should be regularly measured. The position for the beginning of the present year is R.A. $13 \mathrm{~h}, 43 \mathrm{~m} .24 \mathrm{~s}$, and N.P.D. $62^{\circ} 23^{\prime \prime} 6$

The Total Solar Eclipse, 1927, June 29.-We believe the Rev. S. J. Johnson, of Upton Helions, Devon, was the first who pointed out the probable totality of this eclipse for a short interval in this country. It is one of those eclipses in which the moon's augmented semidiameter exceeds that of the sun by a small quantity, even where the sun is on the meridian. The following are approximate elements :-

Conjunction in R. A. 1927 , June 28 , at $18 \mathrm{~h}, 27 \mathrm{~m}$. I4S. G. M.T.

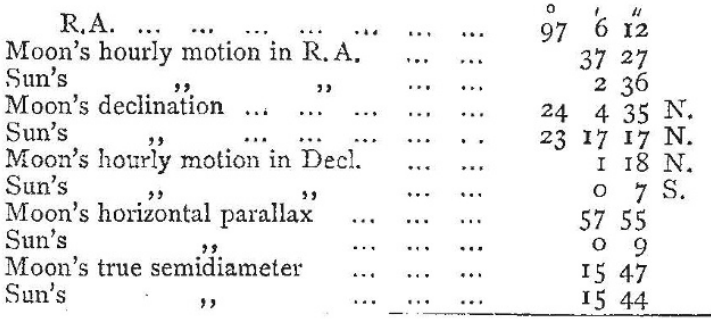

The sidereal time at Greenwich noon on June 29 is $6 \mathrm{~h} .26 \mathrm{~m}$. I7s., and the equation of time $3 \mathrm{~m}$. 35 . subtractive from mean time. The middle of general eclipse at 18h. $23 \mathrm{~m}$. I7s.

Hence the following points on the central line :-

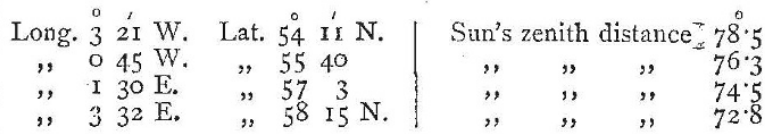

In $1^{\circ} 37^{\prime} \mathrm{W}$. and $55^{\circ} \mathrm{I} 2^{\prime} \mathrm{N}$. totality begins according to the above elements, June 28 at $17 \mathrm{~h}$. $19 \mathrm{~m}$. 3Is. local mean time, and continues only nine seconds. It will be seen that the track of the central line in its passage over England is from Windermere, a little north of Morpeth, to the Northumberland Coast ; it appears to just escape the Isle of Anglesey, but our data are not quite definitive.

MINOR PlanETS,-M. Stéphan has calculated elements of No. I46, discovered by M. Borrelly, from the Marseilles observations of June 9, I8, and 29, which give as a first approximation to the period of revolution, 1627 days; the planet has been named Lucina. Euphrosyne is in opposition about this time, with $57^{\circ}$ South Declination; this body makes one of the widest excursions of any in the group, and may at times be found in Ursa Major. Daphne is the brightest of the small planets now near opposition.

\section{SCIENCE IN GERMANY \\ (From a German Correspondent.)}

$\mathrm{IN}$ continuation of the last report (p. I52) we make the following further communication on Götte's "History of Development." As we have already mentioned, Götte deduces the structure of the embryo from the difference in size and position of the parts resulting from the division of the ovum. He supports this theory by the following observations. In the case of all ova, first of all a difference shows itself in the vertical axis, the parts round the upper pole being smaller and generating quicker than those round the under pole. The ratio of displacement is therefore also much greater in the upper hemisphere; and as this one expands concentrically it overgrows downwards the more bulky lower hemisphere, or causes it to bulge inwards, so that from the ovum which divides into many cell-like pieces, results a beaker-shaped 
formation with double sides; these are the treo original gcrm-layers. The space enclosed by the inner germlayer is the intestinal cavity; the whole formation we call gastrula after Haeckel. As the causes of the formation of the two germ-layers are the same for all animals consisting of more than one cell (matazoa), according to Götte's view, the form of development of the gastrula is therefore common to all, however indiscernible it may often be in the outside appearance. The cause of this is partly that the above-mentioned difference between the upper and lower hemispheres of the ovum varies in magnitude. If this difference is small, the result will be that only a moderate part of the lower hemisphere will be pressed inward, the inner germ-layer remaining simple, as for instance with the lower polypi, which on the whole consist of two layers of cells. As the energy of the inward pressure increases, a third germ-layer, the so-called middle one, is split off the stronger inner one; this third one, from being a simple intermediary layer, may develop and originate many and important organs. If in the dividing ovim only the difference referred to in the vertical axis exist, the gastrula is naturally formed equally in all directions between the two poles, so that if further transformations take place, these likewise occur equally in all directions from the intestinal cavity and its principal axis, and therefore in radiated planes or lines. Thus the difference in the first axis of the ovum, if it acts by itself, always leads to a radiated structure of body which we find with Polypi, Medusæ, Echinoidea, and their relatives. Yet the higher developed representatives of these classes already show here and there, and in unimportant points, indications of a transition to a higher type. If we suppose the two horizontal axes of the ovum to be unequal, then the formation of the gastrula must naturally be unequal likewise. The inequality, which with many of the Vermes already shows itself during the first divisions of the ovum, causes the gastrula to extend in one direction more than in any other, and thus to receive another principal axis. If at the same time the two sides precede in development the other parts, two symmetrical masses are formed, situated opposite one another (germ-streaks), and which approach each other more or less on the stomach side, and there produce certain principal organs. To this transverse divisions may be added, as in the Arthropoda; or this may not occur, as in the Viollusca. Vertebrata finally do not show the preponderance of the first formation on two opposite symmetrical sides of the ovum, but only on one, where the odd germ-streak is situated and indicates the future back. In a manner similar to that of the typical foundation of the embryo, Götte tries to deduce all other phenomena of development not from hypothetical causes of inberitance, but directly from the laws of the formation of the ovum; as, for instance, the whole development of the different organs and tissues. Any essential change in a ceriain animal species must then be deduced from a change in the laws of formation, which are peculiar to the ovum, i.e. its first cause lies in the ovum, and the live animal can never transfer newlygained changes of form directly to the law of formation of its germs, nor thus cause its descendants to inherit them.

\section{NEW DISCOVERY IN CONNECTION WITH THE POTATO DISEASE}

THERE has been hitherto one "missing link" in our 1 knowledge of the life-history of the potato-blight, Peronospora infestans. The non-sexual mode of reproduction by coniclia or zoospores has long beer known; but the sexual mode of reproduction has eluded observation. This link has now been supplied through the researches of Mr. Worthington Smith, who described his discovery in a paper read at the last meeting of the Scientific Committee of the Royal Horticultural Society, and published at length in the Gardener's Chronicle for July 1o. He finds the female organs, the "restingspores " or unfertilised "oospores," and the male organs or "antheridia," in the interior of the tissue of the tuber, stem, and leaf, when in a very advanced stage of decay; and he has actually observed the contact between the two organs in which the process of fecundation consists. In some remarks made at the meeting of the British Association last year by one of our high authorities, it was suggested that we have in the Peronospor $a$ an instance of the phenomenon not infrequent among fungi, known as "alternation of generations " and that the germination of the true spores of the potato-blight must be looked for on some other plant than the potato. Mr. Worthington Smith has, however, looked nearer home, and has proved that the suggestion is not at all events verified in all cases. It is matter of congratulation that, after the lapse of a period of nearly thirty years since the publication of the first important memoir on the subject, this discovery-important alike from a scientific and a practical point of view - has fallen to one of our own countrymen, notwithstanding the foreign aid invoked by the Royal Agricultural Society in settling the still unsolved problems connected with this perplexing pest.

\section{HISTORY OF THE PLAGIOGRAPH}

I SHOULD like to add a few words to my description of the instrument called the Plagiograph * (the $g$ to be pronounced soft, like $j$, as in Genesis, Plagiarist, Oxygen) in NATURE, vol. xii. p. I68, for the purpose of explaining the order of ideas in which it took its rise, and also a very beautiful extension of another recent kinematical invention to which it naturally leads the way, and which, thus generalised, I propose to term the Quadruplane.

The true view of the theory of linkagest is to consider every link as carrying with it an indefinitely extended. plane, and to look upon the question as one of relative

* It may be questioned whether a new-born child can have a history. Perhaps it might have been more correct to have used for my title, "History of the Birth of the Plngirgraph," but this would have been long; moreover, the Plagiograph proves to be an unusually precocious child, having in its very cradle given birth to a greater than itself, the Quadruplane, a fullgrown invention described in the sequel of the text.

It is quite conceivable that the whole universe may constitute one great linkage, i.e. a system of points hound to maintain invariable distances, certain of them from certain others, and that the law of gravitation and similar physical rules for reading off natural phenomena may be the consequences of this condition of things. If the Cosmic linkage is of the kind 1 have called complete, then deterninism is the law of Nature. but, if there be more than one degree of liberty in the system, there will be room reserver for the play of free-will. We shoud thus revert to the Aristotelian view uncler a somewhat wider aspect of circular (the most perfect because the simplest form of motion) being the primary (however recondite) law of cosmical dynamics. Speaking of cosmical laws brings to my mind a reflection I have made upon the new chemical theory of atomicity. Suppose it should turn out that the doctrine of Valence should be confirmed by experience, and that the consequent logico-mathematical theory of colligation containing the necessary laws of consecution, or if cone pleases so to say of cause and effect should plant its foot and introduce a firm basis of predictive science into chemistry, how beautiful will be the a firm basis of this and the physical law of inertia! which really merely affirms the fact of each atom or noint of matter cartying about with it a lertain the fact denoting its communicative and inverse receptive with it a certain number, such case Valency, also a ffirming a te the exact analogue in chemistry to Inertia capacity for colligation, will and might properly assume the name of chemical inertia. differ as egregiously as Isomers in their capacity for forming multifarious attachments.

I I believe it is to Mr. Samuel Roberts that we are indebted for the idea of passing from mere copulated links to planes associated with the links, and for the observation that the order of the corresponding Graphs is not thereby augmented. The substitution of the more general idea of linkage for link-work, and of isolating completely the conception of relative in lieu of absolute motion, is due to the author of these lines. Take the case of a Quadruplane in which the four joints in their natural order of sequence form a contra-parallelogram. It is well known (and the fact has been applied to machinery under the name of "the parallelogram of Reulleux") that the relative motion of an opposite pair of planes may be represented by causing two curves to roll upon each other; but I add that this may be done simultaneously for both pairs of planes, giving rise to a beautiful and previously unthought of double motion of rolling (without slip) between two ellipses for one pair and two hyperbolas for the other pair of planes. This is an immeone pair and two hyperbolas for the other pair of planes. This
diate deduction from the conception of purely relative motion.

Nотв-In the description of the plagiograph, for pointed parallelogram, p. 168, second column, line 14, lege jointed parallelogram. Also a dotted line should be drawn in Fig. $x$ connecting the points 0 and $\mathrm{P}^{\prime}$. 